\title{
Urinary Phytoestrogen Metabolites Positively Correlate with Serum 25(OH)D Level Based on National Health and Nutrition Examination Survey 2009-2010
}

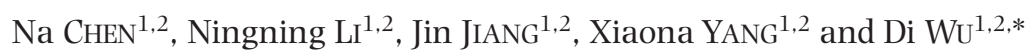 \\ ${ }^{1}$ State Key Laboratory of Reproductive Medicine, Center for Global Health, School of Public Health, \\ Nanjing Medical University, Nanjing, China \\ ${ }^{2}$ Key Laboratory of Modern Toxicology of Ministry of Education, School of Public Health, \\ Nanjing Medical University, Nanjing, China
}

(Received March 29, 2021)

\begin{abstract}
Summary Studies showed that vitamin D (25-hydroxyvitamin D) level in the human blood circulation could be affected by exogenous estrogen exposure. This study aims to explore the relationships between urinary phytoestrogens metabolites and serum total 25(OH)D in general population, urinary phytoestrogens metabolites (daidzein, enterodiol, enterolactone, equol, genistein and $o$-desmethylangolensin). Totally 2,609 adults $\geqslant 6$ y old from the 2009-2010 National Health and Nutrition Examination Surveys (NHANES) were recruited into the cross-sectional analyses and information including demographic, socioeconomic, examinations and laboratory test were collected. All analyses were performed using Stata13.0, one-way analysis of variance and multivariable regression were utilised according to data characteristics, respectively. It showed that age, race, education level, body mass index (BMI), and sampling season had significant effects on serum 25(OH)D level (all $p<0.001$ ). In the whole population, urinary enterodiol and equol were significantly positively associated with serum total $25(\mathrm{OH}) \mathrm{D}$ level $(\beta=0.86,95 \% \mathrm{CI}=0.08-1.65$, $p<0.05 ; \beta=1.68,95 \% \mathrm{CI}=0.91-2.45, p<0.001)$. Equol was also found significantly positively correlated with total $25(\mathrm{OH}) \mathrm{D}$ in both female and male separately $(\beta=1.69$, $95 \% \mathrm{CI}=0.51-2.87, p<0.05 ; \beta=1.66,95 \% \mathrm{CI}=0.63-2.69, p<0.05)$. Phytoestrogen concentrations in the urinary and $25(\mathrm{OH}) \mathrm{D}$ levels in the serum had proved a positive correlation in our study, which provide theoretical basis and reference for the dietary nutrient intake in the population.
\end{abstract}

Key Words NHANES, urinary phytoestrogen, 25-hydroxyvitamin D, enterodiol, equol

Vitamin D in the human body comes from endogenous production and dietary uptake. It is generated mainly through the photolytic reaction of 7-dehydrocholesterol. After the hydroxylation by 25 -hydroxylase in hepatomicrosome and then $1 \alpha$-hydroxylation in renal cell mitochondria, vitamin D can be transformed into $25(\mathrm{OH}) \mathrm{D}$, which is bioactive and can bind specifically to intracellular vitamin D receptors (1-4). Thus serum 25 concentration had been shown to be the best indicator of human vitamin D level (5). The most important physiological function of vitamin $\mathrm{D}$ is to regulate calcium and phosphorus metabolism in the skeletal system. Currently researchers found that vitamin D might be a protective factor against viruses, such as COVID-19 $(6,7)$.

The deficiency of vitamin $\mathrm{D}$ in the human body is a ubiquitous public health problem around the world and leads to multiple systemic dysfunctions $(8-10)$. Serum vitamin D concentration is affected by not only individual varieties, but also exposure of environmental factors especially chemicals with estrogenic activities (11,

*To whom correspondence should be addressed.

E-mail: diwu@njmu.edu.cn
12). Johns et al. found that adults exposed to phthalates and bisphenol A had higher serum levels of $25(\mathrm{OH}) \mathrm{D}$ (12).

Phytoestrogen, which is one big group of EDCs, contains natural non-steroidal compounds with estrogenic activities and has been used in hormone replacement therapy (13). Phytoestrogens were found in a wide variety of drugs and our daily diet $(14,15)$, and their analogues could increase the expression of $1 \alpha$-hydroxylase and further promote $1,25-(\mathrm{OH})_{2} \mathrm{D}_{3}$ synthesis (16). Previous studies suggested that serum $25(\mathrm{OH}) \mathrm{D}$ concentration was elevated after phytoestrogen treatment in women $(5,17-20)$. We would like to further explore the relationship between the phytoestrogen levels and blood circulating vitamin D in human body. Accordingly, the aim of this study is to analyze the associations between the levels of urinary phytoestrogen metabolites and the serum $25(\mathrm{OH}) \mathrm{D}$ level in the general population by dealing with the data from the National Health and Nutrition Examination Surveys (NHANES) 2009-2010.

\section{MATERIALS AND METHODS}

The information and data were obtained from NHANES, 2009-2010 (https://wwwn.cdc.gov). NHANES 


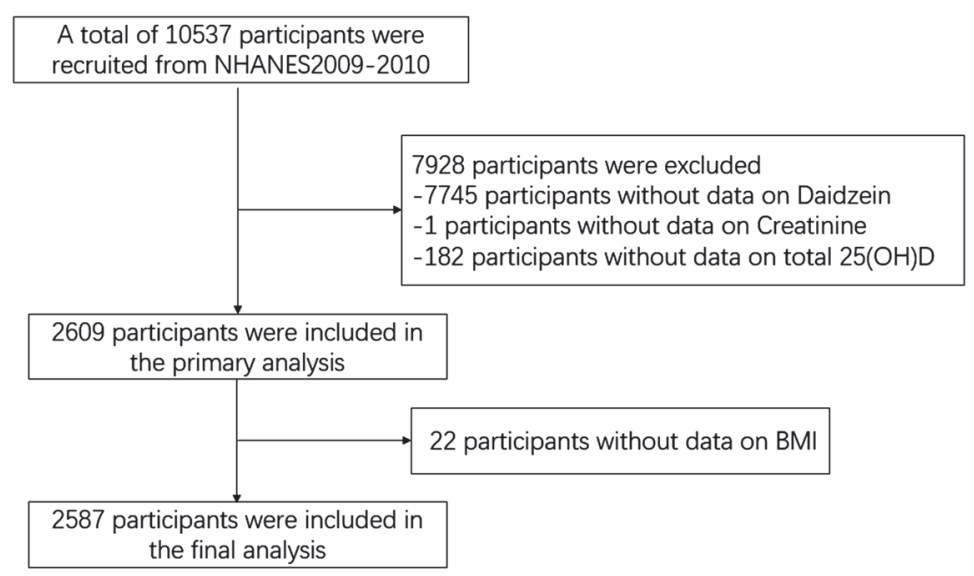

Fig. 1. Flowchart describing the process used for the final selection of participants from NHANES 2009-2010.

is a program of studies designed to evaluate the health and nutritional status of adults and children in the United States. This cross-sectional investigation containing demographic, interview, examinations, questionnaire, and laboratory data, which are available through an extensive series of scientific publications and articles. The data used for this study were publicly available. Prior to public release, the study protocol (continuation of Protocol No. 2005-06) was approved by the NCHS Research Ethics Review Board. In our study, a total of 10,537 participants were recruited from NHANES 2009-2010, but totally 2,609 people (1,299 males and 1,310 females, aged at $6 \mathrm{y}$ or older), whose data of urinary phytoestrogens, urinary creatinine, and serum 25(OH)D were complete, were included in our primary analyses and totally 2,587 participants (22 participants without data on body mass index (BMI)) were included in final regression analyses by covariates (Fig. 1).

The urinary phytoestrogen metabolites (daidzein, enterodiol, enterolactone, equol, genistein and $o$-desmethylangolensin) and serum vitamin $\mathrm{D}\left(25(\mathrm{OH}) \mathrm{D}_{2}\right.$ and $\left.25(\mathrm{OH}) \mathrm{D}_{3}\right)$ of the participants from NHANES 2001-2010 were detected by the Division of Laboratory Sciences, the National Centre for Environmental Health in Centre for Disease Control and Prevention using high performance liquid chromatography-atmospheric pressure photoionization-tandem mass spectrometry (HPLC-APPI-MS/MS). The limits of detection (LODs) of daidzein, enterodiol, enterolactone, equol, genistein and $o$-desmethylangolensin were $0.40,0.04$, $0.10,0.06,0.20$ and $0.20 \mathrm{ng} / \mathrm{mL}$ respectively $(21,22)$.

Information on race/ethnicity, 6-mo sampling period, education level, family income to poverty ratio (PIR), BMI, age, and 30-d vitamin D supplementary was collected from demographic questionnaire and each was considered as potential confounding variables. The whole people had been divided into five race groups (Non-Hispanic White, Non-Hispanic Black, Mexican American, Other Hispanic, and Other Race), two types of 6-mo sampling period (summer months: May 1stOctober 31st; winter months: November 1st-April 30th), three education level group (Less than high school, High school/GED, and More than high school), and two PIR group (PIR $<1$ or PIR $\geq 1$ ). Also, there are four groups of BMI (Underweight: <18.5, Normal weight: 18.5-25, Overweight: 25-30, and Obesity: $\geq 30$ ) (23), and five groups of age ( 6 to $<12,12$ to $<20$, 20 to $<40,40$ to $<60$, and 60 to $<80$ ). Moreover, 30-d vitamin D supplementary were obtained from dietary analysis, and two categories on 30-d vitamin D supplement use were defined as: No: without vitamin D supplement; Yes: with vitamin D supplement.

STATA Version 13 (Stata Corp. College Station, Texas, USA) was used to do the analysis. Urinary phytoestrogen concentration was standardised with creatinine and then normal distribution was checked. Data had been natural logarithm (ln)-transformed when the right-skewed distribution was found.

One-way ANOVA was used to analyze the difference of serum vitamin D levels in subgroups of race, education, age and BMI, and then Bonferroni was applied to make multiple comparisons among groups. Multivariable regression models by gender were used to exclude its effect in overall population. In the final regression model, urinary phytoestrogen was adjusted by Race (categorical), Sampling season (categorical), Education level (categorical), PIR (continuous), BMI (continuous), Age (continuous), and 30-d Vitamin D supplement (categorical). To increase the accuracy of analysis, analysis weights were applied throughout the analysis process. The associations between each urinary phytoestrogens and serum vitamin D were examined through linear regression analysis.

Because isoflavones and lignans are the most common phytoestrogens in human diet $(24,25)$, we also examined the associations of total serum 25(OH)D with the sum of isoflavones (equol, daidzein, genistein, and $o$-desmethylangolensin), the sum of lignans (enterolactone, and enterodiol), and the sum of all phytoestrogens, repectively. Both appropriate weighted and unweighted analyses were utilised. It was considered statistically significant when $p<0.05$.

\section{RESULTS}

Demographic population characteristics of 2,609 
Table 1. Demographic and laboratory characteristics in NHANES 2009-2010 population.

\begin{tabular}{|c|c|c|c|c|}
\hline Population characteristics & $n$ & Unweighted (\%) & Weighted (\%) & $\begin{array}{c}\text { Total } 25(\mathrm{OH}) \mathrm{D} \text { levels, } \\
\text { weighted mean }(\mathrm{SD}) \\
(\mathrm{nmol} / \mathrm{L})\end{array}$ \\
\hline \multicolumn{5}{|l|}{$\operatorname{Age}^{* * *}$} \\
\hline 6 to $<12$ & 300 & 11.50 & 7.02 & $70.83(20.78)^{1}$ \\
\hline 12 to $<20$ & 409 & 15.68 & 11.71 & $64.99(23.30)^{2}$ \\
\hline 20 to $<40$ & 650 & 24.91 & 30.50 & $62.72(25.33)^{3}$ \\
\hline 40 to $<60$ & 617 & 23.65 & 30.64 & $69.38(26.50)^{4}$ \\
\hline 60 to $<80$ & 633 & 24.26 & 20.13 & $73.69(28.65)$ \\
\hline \multicolumn{5}{|l|}{$\operatorname{Race}^{* * *}$} \\
\hline Mexican American & 570 & 21.85 & 10.16 & $54.39(16.82)^{5}$ \\
\hline Other Hispanic & 268 & 10.27 & 5.09 & $59.39(19.63)^{6}$ \\
\hline Non-Hispanic White* & 1,116 & 42.78 & 64.99 & $75.63(25.36)^{7}$ \\
\hline Non-Hispanic Black & 491 & 18.82 & 11.82 & $48.47(21.78)^{8}$ \\
\hline Other Race & 164 & 6.29 & 7.94 & $55.10(24.00)$ \\
\hline \multicolumn{5}{|l|}{ Education level*** } \\
\hline Less than highschool & 1,192 & 45.69 & 32.10 & $64.54(23.55)$ \\
\hline High school/GED & 475 & 18.21 & 20.80 & $66.78(27.30)$ \\
\hline More than highschool & 942 & 36.11 & 47.10 & $70.49(27.14)^{9}$ \\
\hline \multicolumn{5}{|l|}{ BMI, $\mathrm{kg} / \mathrm{m}^{2 * * *}$} \\
\hline Underweight $(<18.5)$ & 258 & 9.97 & 7.49 & $71.23(22.38)$ \\
\hline Normal weight (18.5-25) & 828 & 32.01 & 33.34 & $71.03(27.39)$ \\
\hline Overweight $(25-30)$ & 720 & 27.83 & 28.35 & $69.20(25.33)$ \\
\hline Obesity $(\geq 30)$ & 781 & 30.19 & 30.82 & $62.44(25.80)^{10}$ \\
\hline \multicolumn{5}{|l|}{ 30-d vitamin D supplement ${ }^{* * *}$} \\
\hline Yes & 779 & 29.86 & 36.17 & $79.60(26.74)$ \\
\hline No & 1,830 & 70.14 & 63.83 & $61.12(23.39)$ \\
\hline \multicolumn{5}{|l|}{ PIR category*** } \\
\hline$<1$ & 844 & 32.35 & 22.74 & $61.17(24.05)$ \\
\hline$\geq 1$ & 1,765 & 67.65 & 77.26 & $69.76(26.49)$ \\
\hline \multicolumn{5}{|l|}{ Sampling season*** } \\
\hline Winter months & 1,239 & 47.49 & 41.42 & $60.76(24.06)$ \\
\hline Summer months & 1,370 & 52.51 & 58.58 & $72.79(26.51)$ \\
\hline
\end{tabular}

$* p<0.05$.

${ }^{1}$ The group of age 6 to 12 had significant higher $25(\mathrm{OH}) \mathrm{D}$ level comparing to 12 to 20 group and 20 to 40 group $(p<0.05$, $p<0.001$, respectively).

${ }^{2}$ The group of age 12 to 20 had significantly lower $25(\mathrm{OH}) \mathrm{D}$ level comparing to 60 to 80 group $(p<0.001)$.

${ }^{3}$ The group of age 20 to 40 had significantly lower $25(\mathrm{OH}) \mathrm{D}$ level comparing to 40 to 60 group and 60 to 80 group $(p<0.001, p<0.001$, respectively).

${ }^{4}$ The group of 40 to 60 had significantly lower $25(\mathrm{OH}) \mathrm{D}$ level comparing to 60 to 80 group $(p<0.05)$.

${ }^{5}$ Mexican American had significantly lower 25(OH)D level comparing to Other Hispanic, Non-Hispanic White (both $p<0.05)$ and they had significantly higher 25(OH)D level comparing to Non-Hispanic Black $(p<0.001)$.

${ }^{6}$ Other Hispanic had significantly lower 25(OH)D level comparing to Non-Hispanic White $(p<0.001)$, and significantly higher 25(OH)D level comparing to Non-Hispanic Black $(p<0.05)$.

${ }^{7}$ Non-Hispanic White had significantly higher 25(OH)D level comparing to Non-Hispanic Black and Other Race (both $p<0.001)$.

${ }^{8}$ Non-Hispanic Black had significant lower 25(OH)D level comparing to Other Race $(p<0.05)$.

9 "More than highschool" group had significantly higher $25(\mathrm{OH}) \mathrm{D}$ level compared to "Less than highschool" group $(p<0.001)$.

${ }^{10}$ Obesity group had significantly lower $25(\mathrm{OH}) \mathrm{D}$ level compared to underweight group, normal weight group, and overweight group (all $p<0.001$ ).

people recruited in NHANES 2009-2010 were listed in Table 1. In weighted analysis, it was shown that $30.64 \%$ participants were $40-60$ y old and $64.99 \%$ were NonHispanic White. Nearly half participants' educational level was more than high school. Overweighed participants occupied $28.35 \%$ and $30.82 \%$ reached obesity. Participants with PIR $\geq 1$ occupied $77.26 \%$ and sampling season of $58.58 \%$ was summer months. In un- weighted analysis, $24.91 \%$ participants were $20-40$ y old and $42.78 \%$ participant were Non-Hispanic. The participants whose education level was less than high school account for $45.69 \%$. Moreover, $27.83 \%$ participants were over weighted, and $30.19 \%$ reached obesity.

Different subgroups of $25(\mathrm{OH}) \mathrm{D}$ level were also presented in Table 1. In weighted analysis, age had a positively effect on 25(OH)D levels $(p<0.0001)$. Specifically, 
Table 2. Weighted, creatinine-corrected phytoestrogens concentrations.

\begin{tabular}{|c|c|c|c|c|c|c|c|}
\hline \multirow{2}{*}{ Urinary analyte } & \multirow{2}{*}{$\begin{array}{l}\text { Detection } \\
\text { frequency } \\
(\%)\end{array}$} & \multirow{2}{*}{$\begin{array}{c}\text { Geometric } \\
\text { mean }(\mathrm{GSD}) \\
(\mathrm{ng} / \mathrm{mL})\end{array}$} & \multicolumn{5}{|c|}{ Selected percentiles (ng/mL) } \\
\hline & & & 25 th & 50 th & 75 th & 90th & 95th \\
\hline \multicolumn{8}{|l|}{ Lignans } \\
\hline Enterodiol & 99.54 & $4.25(7.27)$ & 1.89 & 4.70 & 10.85 & 28.75 & 52.29 \\
\hline Enterolactone & 100 & $23.21(41.53)$ & 8.28 & 30.25 & 78.57 & 185.12 & 292.94 \\
\hline \multicolumn{8}{|l|}{ Isoflavones } \\
\hline Daidzein & 99.92 & $7.41(12.97)$ & 1.94 & 5.55 & 21.97 & 80.88 & 194.69 \\
\hline Genistein & 100 & $3.49(5.99)$ & 0.97 & 2.54 & 9.90 & 37.07 & 87.50 \\
\hline$o$-Desmethylangolenin & 95.25 & $0.51(1.21)$ & 0.08 & 0.38 & 2.36 & 13.97 & 43.53 \\
\hline Equol & 99.89 & $0.84(1.21)$ & 0.37 & 0.77 & 1.65 & 3.62 & 7.29 \\
\hline Sum of phytoestrogens & & $72.85(97.40)$ & 31.87 & 69.68 & 166.22 & 399.53 & 695.47 \\
\hline
\end{tabular}

compared to the groups aged 12 to 20 and 20 to 40 , the group aged 6 to 12 had significant higher $25(\mathrm{OH}) \mathrm{D}$ level $(p<0.05, p<0.001$, respectively). Compared to aged 60 to 80 , aged 12 to 20 had significantly lower $25(\mathrm{OH}) \mathrm{D}$ level $(p<0.001)$. The group aged 20 to 40 had significantly positively lower $25(\mathrm{OH}) \mathrm{D}$ level compared to the group aged 40 to 60 and 60 to $80(p<0.001, p<$ 0.001 , respectively). The 40 to 60 group had significantly lower $25(\mathrm{OH}) \mathrm{D}$ level compared to the 60 to 80 group $(p<0.05)$.

Race had a significant effect on 25(OH)D level $(p<$ 0.0001). Particularly, Mexican American had significantly positively lower $25(\mathrm{OH}) \mathrm{D}$ level compared to Other Hispanic, Non-Hispanic White (both $p<0.05$ ) and they had significantly higher $25(\mathrm{OH}) \mathrm{D}$ level compared to Non-Hispanic Black $(p<0.001)$. Other Hispanic had positively lower $25(\mathrm{OH}) \mathrm{D}$ level compared to NonHispanic White $(p<0.001)$, and significantly higher 25(OH)D level compared to Non-Hispanic Black $(p<$ 0.05). Non-Hispanic White had significantly higher 25(OH)D level compared to Non-Hispanic Black and Other Race (both $p<0.001$ ). The group of Non-Hispanic Black had significantly positively lower $25(\mathrm{OH}) \mathrm{D}$ level compared to Other Race $(p<0.05)$.

Education level had a significant effect on 25(OH)D level $(p<0.0001)$. The "More than high school" had significantly higher $25(\mathrm{OH}) \mathrm{D}$ level compared to the "Less than high school" $(p<0.001)$.

BMI had a significant effect on $25(\mathrm{OH}) \mathrm{D}$ level $(p<$ 0.0001). Specifically, compared to the group of underweight, normal weight, and overweight, the group of obesity had significantly lower $25(\mathrm{OH}) \mathrm{D}$ level (all $p<$ 0.001).

Participants investigated in summer months had significantly positively higher $25(\mathrm{OH}) \mathrm{D}$ level than in winter months $(p<0.0001)$. Those who reported not taking vitamin D supplement in the past $30 \mathrm{~d}$ had significantly positively higher $25(\mathrm{OH}) \mathrm{D}$ level than the person with vitamin D supplement $(p<0.001)$.

The distributions of weighted, geometric means and creatinine-corrected urinary phytoestrogens levels (selected percentile) were presented in Table 2. Enterolactone level was the highest among phytoestrogens, and equol level was the lowest.

In the crude model, lignans, equol and sum of phytoestrogens were significantly positively associated with total $25(\mathrm{OH}) \mathrm{D}$ in gender-stratified model and overall population (all $p<0.05$ ). These results were also observed in weighted and unweighted analyses (Table 3). In the unweighted crude analysis, isoflavones were significantly positively associated with total $25(\mathrm{OH}) \mathrm{D}$ in both females $(\beta=0.96,95 \% \mathrm{CI}=0.05-1.86, p<0.05)$ and overall population $(\beta=0.72,95 \% \mathrm{CI}=0.13-1.31$, $p<0.05)$.

In unweighted analysis, after having been adjusted with age, race, education, BMI, 30-d vitamin D supplement use, PIR, sampling season in male and female models, the association between equol and $25(\mathrm{OH}) \mathrm{D}$ was positively significant in both female-stratified and male-stratified models $(\beta=2.20,95 \% \mathrm{CI}=1.27-3.14$, $p<0.001 ; \beta=1.84,95 \% \mathrm{CI}=1.03-2.65, p<0.001)$. In unweighted analysis, after having been adjusted with gender variable, the results showed that equol and $25(\mathrm{OH}) \mathrm{D}$ had significant association in the whole population $(\beta=2.02,95 \% \mathrm{CI}=1.40-2.63, p<0.001)$ (Table $4)$. In both the whole population and female population, the associations were significant between $25(\mathrm{OH}) \mathrm{D}$ and enterodiol $(\beta=0.80,95 \% \mathrm{CI}=0.25-1.36, p<0.05$; $\beta=1.27,95 \% \mathrm{CI}=0.47-2.07, p<0.05$, respectively). In weighted analysis, significantly positive associations between enterodiol and $25(\mathrm{OH}) \mathrm{D}$ in both the whole population and in female population had been detected $(\beta=0.86,95 \% \mathrm{CI}=0.08-1.65, p<0.05 ; \beta=1.10,95 \% \mathrm{CI}=$ $0.01-2.20, p<0.05$, respectively) (Table 4). Results also showed significantly positive relationships between equol and $25(\mathrm{OH}) \mathrm{D}$ in the whole population, in males and females $(\beta=1.68,95 \% \mathrm{CI}=0.91-2.45, p<0.001$; $\beta=1.69,95 \% \mathrm{CI}=0.51-2.87, p<0.05 ; \beta=1.66,95 \% \mathrm{CI}=$ $0.63-2.69, p<0.05)$.

\section{DISCUSSION}

In this study, urinary phytoestrogen and serum $25(\mathrm{OH}) \mathrm{D}$ levels of 2,609 participants from NHANES 2009-2010 were analyzed and results showed that all the demographic factors (age, race, education, BMI, 30-d vitamin D supplement use, PIR, sampling season) 

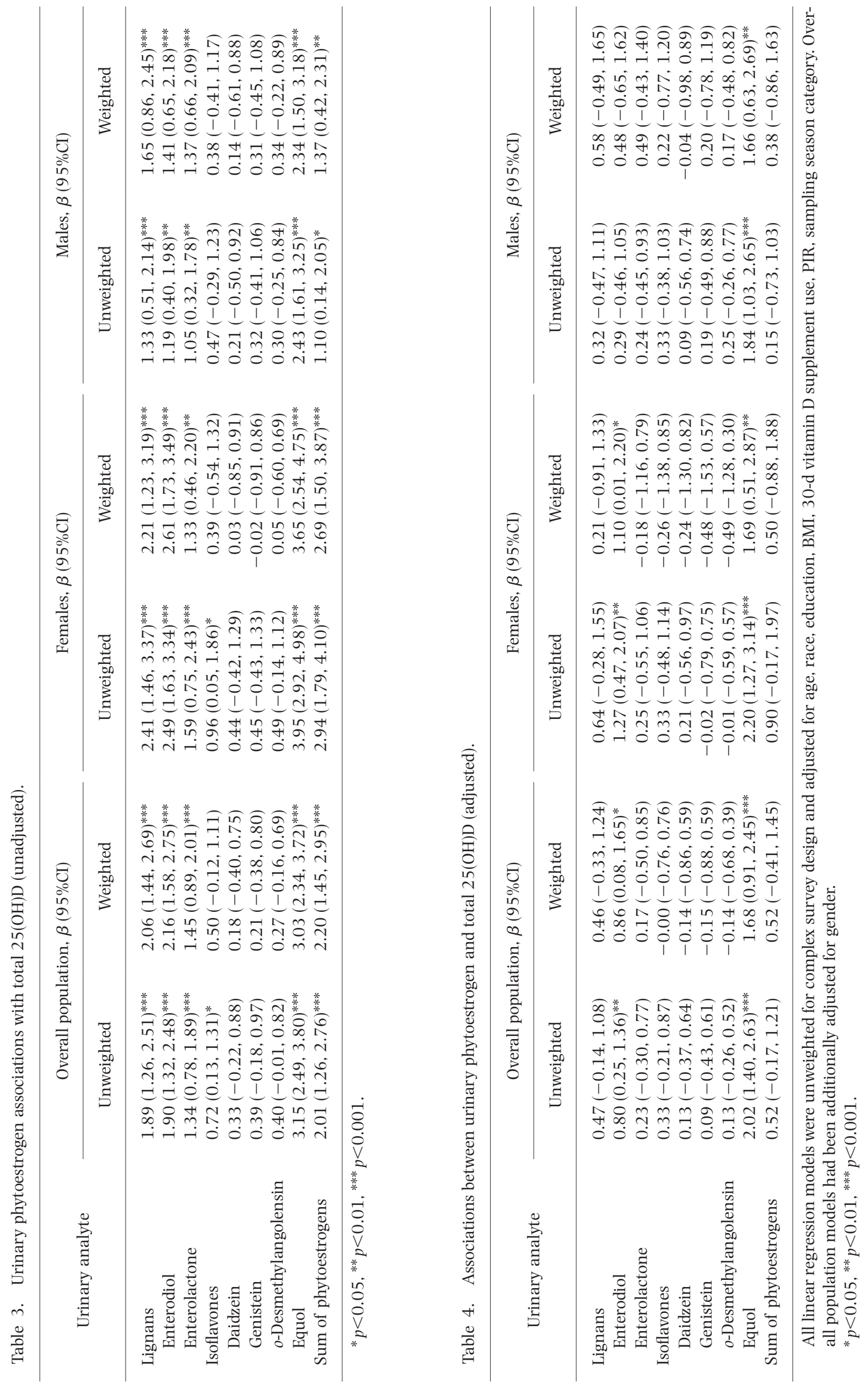
had significant effects on serum 25(OH)D concentration.

Compared to peoples aged 12-40, children and old people were paid more attention and had more possibilities to develop vitamin D deficiency. They might prefer to take dietary supplements, which contained vitamin $\mathrm{D}$, to prevent disease (26-28). That might be the reason why this age group had more serum vitamin D than peoples aged 12-40. Different dietary cultures and vitamin D metabolism ability in different race could affected serum vitamin D level $(29,30)$. As a result, serum vitamin D level was species-specific. With the improvement of education level, the medical theories especially nutrition conceptions would be more likely to be accepted by the population and further affected their daily-care behaviors. People with good education tended to maintain a healthy diet (31). High-income families were more inclined to use dietary supplements and fortified foods. They might have more ways to reach vitamin D supplement $(32,33)$. Thus, people whose family PIR was big than 1 had higher serum 25(OH)D concentration than people whose family PIR was less than 1 . Moreover, serum vitamin D levels could also increase after sunlight and ultraviolet light exposure $(34,35)$. Therefore, peoples sampled in summer months, exposed to more sunlight and ultraviolet light, had more vitamin D in serum compared to peoples in winter months.

Our study clearly showed that urinary phytoestrogens or their metabolites in human were significantly positively correlated with serum $25(\mathrm{OH}) \mathrm{D}$ concentration. The levels of urinary phytoestrogen metabolites might be markers to indicate serum 25(OH)D level, which could provide a non-invasive inspection means of vitamin D.

Although the significant relationship between phytoestrogens and serum 25(OH)D concentration had been found, whether there was a direct causal link between these two still need to be explored. Since phytoestrogen acts in the body as an exogenous estrogen, it could act as a cause. Previous studies suggested estrogenic chemicals intake could lead the increase of circulating 1,25- $(\mathrm{OH})_{2} \mathrm{D}_{3}$ in females in both human and animals. As early as 1989 , studies had shown that circulating 1,25- $(\mathrm{OH})_{2} \mathrm{D}_{3}$ in postmenopausal women increased after exogenous estrogen uptake $(36,37)$. In a survey of 1,662 African American women aged 23-34, the concentration of serum $25(\mathrm{OH}) \mathrm{D}$ increased following the recent use of estrogen-containing contraceptives (20). Combined treatment of isoflavones and calcium had been found to prevent vitamin D loss and the blood 25(OH)D level was partially restored after cowpea isoflavones supplementation in rat (38).

$1,25-(\mathrm{OH})_{2} \mathrm{D}_{3}$ receptor (VDR) might play a key role in the process of elevated $25(\mathrm{OH}) \mathrm{D}$ by phytoestrogen. Previous studies had shown that phytoestrogens could up-regulate VDR protein expression, thereby enhancing cellular sensitivity to $1,25-(\mathrm{OH})_{2} \mathrm{D}_{3}$. An early study demonstrated that $17 \beta$-estradiol could increase the expression of VDR in human osteoblast-like cells and regulate the biological effects of $1,25-(\mathrm{OH})_{2} \mathrm{D}_{3}$ (39).
Duque and his colleagues found that the expression of VDR in skeletal muscle decreased with age and estrogen attenuation in mice, but it could be restored after estradiol supplementation by enhancing the bioactivity of VDR (40). Although increased VDR might also elevated CYP24A1 transcription, which catabolizes 25D3 and $1,25 \mathrm{D} 3$, estrogen or phytoestrogen had been reported to inhibit CYP24A1 $(41,42)$. Thus estrogen or phytoestrogen could help increase VDR sensitivity and decrease $25(\mathrm{OH}) \mathrm{D}$ catabolism at the same time.

Our results showed among the phytoestrogen metabolites, enterodiol and equol were more related with serum 25(OH)D level in both weighted models and unweighted models, with/without covariates being taken into the regression model in the whole population. Specific metabolism might be involved. Enterodiol and equol could be metabolised from polyphenols and daidzein by intestinal flora and had more estrogenic and antioxidant activity than their precursors (43-46). Equol could affected VDR expression by activating extracellular signal-regulated kinase signaling pathway and regulating VDR gene Sp-1 site (47). On the other hand, VDR deficiency in the intestine has been reported to affect the intestinal flora and thus local equol production is disrupted (48). Since enterobacteriaceae is largely involved in the metabolism of phytoestrogen, internal phytoestrogen metabolite levels may vary due to individual intestinal flora structure difference (49). This might partly explain why urinary phytoestrogen concentrations varied greatly in our results. It could be inferred that antibiotic application could also affect phytoestrogen metabolism. However, antibiotics-taken information was not provided by NHANES. It would be helpful to include antibiotics questions in the survey in the future. Enterodiol is one type of lignans and mainly ingested from beverages, vegetables, nuts and seeds, bread, and fruits $(50,51)$. Equol, one type of isoflavones, is mainly ingested from legumes such as soy, beans $(52,53)$. Thus, taking these foods, contain enterodiol and equol, may affect the levels of serum $25(\mathrm{OH}) \mathrm{D}$ level, which provides a new way to increase the levels of serum $25(\mathrm{OH}) \mathrm{D}$ level. The intake of these foods may be closely related with urinary phytoestrogen metabolite concentrations. The detailed information on intake and status of phytoestrogen-contained foods could not be obtained from NHANES. Well designed surveries focusing on food intake and internal phytoestrogen concentrations would be launced to analyzed their association further.

Sex-stratified analysis showed that the correlations urinary phytoestrogen metabolite concentrations and serum 25(OH)D level were stronger in women than in men. Phytoestrogens mainly acted by binding to the estrogen receptor (ER) which was expressed more in females than in males $(13,54,55)$. Some behaviors such as taking oral contraceptives and wearing sunscreen, which were observed more in women than in men also contributed to the sex-specific difference in the relationship between phytoestrogens and the vitamin D level $(56,57)$. 
There is no reported mechanism clearly explaining the correlation between urinary phytoestrogens and vitamin D. Even if phytoestrogen metabolites could activate the transcription mechanism via VDR, the mechanism that promotes the expression and activity of CYP27A1, which metabolizes vitamin D to 25-OH-D, is still unknown. More details need to be explored. The correlation we found was based on the observation in the population. Scientific hypotheses could be made and tested to reveal the mechanism underlying.

Our study results indicated a significant correlation between urinary phytoestrogen concentrations and serum 25(OH)D level. Specific phytoestrogen metabolites enterodiol and equol were closely related to the level of vitamin D in human body. More human investigations and animal experiments would verify the urinary phytoestrogen metabolites as the new biomarker of vitamin D and the possibility of supplying vitamin D by increasing phytoestrogen-containing food intake.

\section{Authorship}

Methodology, investigation, data curation, writingoriginal draft, validation: NC; conceptualization, methodology, investigation, formal analysis, writing-review \& editing: NL; methodology, investigation, data curation: JJ; methodology, investigation: XY; project administration, supervision, writing-review \& editing: DW.

$\mathrm{NC}$ and NL contributed equally to this work.

\section{Disclosure of state of COI}

The authors declare that they have no known competing financial interests or personal relationships that could have appeared to influence the work reported in this paper.

\section{Data accessibility statement}

The data were from NHANES, 2009-2010. NHANES is an ongoing cross-sectional study containing demographic, interview, examinations, questionnaire, and laboratory data,designed to assess the health and nutrition status of general US population.

\section{REFERENCES}

1) Souberbielle JC. 2014. Metabolism and effects of vitamin D. Definition of vitamin D deficiency. Biol Aujourdhui 208: 55-68.

2) Carlberg C, Munoz A. 2020. An update on vitamin D signaling and cancer. Semin Cancer Biol 20: S1044579X(20)30114-0.

3) Cheng CY, Slominski AT, Tuckey RC. 2016. Hydroxylation of 20-hydroxyvitamin D3 by human CYP3A4. J Steroid Biochem Mol Biol 159: 131-141.

4) Tuckey RC, Tang EKY, Maresse SR, Delaney DS. 2019. Catalytic properties of 25-hydroxyvitamin D3 3-epimerase in rat and human liver microsomes. Arch Biochem Biophys 666: 16-21.

5) Moller UK, Streym S, Jensen LT, Mosekilde L, Schoenmakers I, Nigdikar S, Rejnmark L. 2013. Increased plasma concentrations of vitamin D metabolites and vitamin D binding protein in women using hormonal contraceptives: a cross-sectional study. Nutrients 5:
3470-3480.

6) Mitchell F. 2020. Vitamin-D and COVID-19: do deficient risk a poorer outcome? Lancet Diabetes Endocrinol 8: 570.

7) Amrein K, Scherkl M, Hoffmann M, NeuwerschSommeregger S, Kostenberger M, Tmava Berisha A, Martucci G, Pilz S, Malle O. 2020. Vitamin D deficiency 2.0: an update on the current status worldwide. Eur J Clin Nutr 74(11): 1498-1513.

8) Ganji V, Zhang X, Tangpricha V. 2012. Serum 25-hydroxyvitamin D concentrations and prevalence estimates of hypovitaminosis D in the U.S. population based on assay-adjusted data. J Nutr 142: 498-507.

9) Autier P, Boniol M, Pizot C, Mullie P. 2014. Vitamin D status and ill health: a systematic review. Lancet Diabetes Endocrinol 2: 76-89.

10) Gromova O, Doschanova A, Lokshin V, Tuletova A, Grebennikova G, Daniyarova L, Kaishibayeva G, Nurpeissov T, Khan V, Semenova Y, Chibisova A, Suzdalskaya N, Aitaly Z, Glushkova N. 2020. Vitamin D deficiency in Kazakhstan: Cross-sectional study. J Steroid Biochem Mol Biol 199: 105565.

11) Ross AC, Gallo RL, Jones G, Kovacs CS, Mayne ST, Rosen CJ, Shapses SA, Manson JE, Abrams SA, Aloia JF, Brannon PM, Clinton SK, Durazo-Arvizu RA, Gallagher JC. 2011. The 2011 report on dietary reference intakes for calcium and vitamin D from the Institute of Medicine: What clinicians need to know. J Clin Endocrinol Metab 96: 53-58.

12) Johns LE, Meeker JD, Ferguson KK. 2016. Relationships between urinary phthalate metabolite and bisphenol A concentrations and vitamin D levels in U.S. adults: National Health and Nutrition Examination Survey (NHANES), 2005-2010. J Clin Endocrinol Metab 101: 4062-4069.

13) Petrine JCP, Bianco-Borges BD. 2021. The influence of phytoestrogens on different physiological and pathological processes: An overview. Phytother Res 35(1): 180197.

14) Rietjens I, Louisse J, Beekmann K. 2017. The potential health effects of dietary phytoestrogens. Br J Pharmacol 174: $1263-1280$.

15) Seyed Hameed AS, Rawat PS, Meng X, Liu W. 2020. Biotransformation of dietary phytoestrogens by gut microbes: A review on bidirectional interaction between phytoestrogen metabolism and gut microbiota. Biotechnol Adv 43: 107576.

16) Somjen D, Katzburg S, Sharon O, Posner GH, Jaccard N, Hendel D, Tamir S, Vaya J. 2011. Mutual interaction of special phytoestrogenic compounds, their synthetic carboxy-derivatives and the less-calcemic vitamin D analog activities in human derived female cultured osteoblasts. J Steroid Biochem Mol Biol 127: 351-357.

17) Millen AE, Wactawski-Wende J, Pettinger M, Melamed ML, Tylavsky FA, Liu S, Robbins J, LaCroix AZ, LeBoff MS, Jackson RD. 2010. Predictors of serum 25hydroxyvitamin D concentrations among postmenopausal women: the Women's Health Initiative Calcium plus Vitamin D clinical trial. Am J Clin Nutr 91: 1324 1335.

18) Bansal N, Katz R, de Boer IH, Kestenbaum B, Siscovick DS, Hoofnagle AN, Tracy R, Laughlin GA, Criqui MH, Budoff MJ, Li D, Ix JH. 2013. Influence of estrogen therapy on calcium, phosphorus, and other regulatory hormones in postmenopausal women: the MESA study. $J$ 
Clin Endocrinol Metab 98: 4890-4898.

19) Garcia-Bailo B, Karmali M, Badawi A, El-Sohemy A. 2013. Plasma 25-hydroxyvitamin D, hormonal contraceptive use, and cardiometabolic disease risk in an ethnically diverse population of young adults. J Am Coll Nutr 32: 296-306.

20) Harmon QE, Umbach DM, Baird DD. 2016. Use of estrogen-containing contraception is associated with increased concentrations of 25-hydroxy vitamin D. J Clin Endocrinol Metab 101: 3370-3377.

21) Hou D, Hong M, Wang K, Yan H, Wang Y, Dong P, Li D, Liu K, Zhou Z, Zhang D. 2021. Prokaryotic community succession and assembly on different types of microplastics in a mariculture cage. Environ Pollut 268: 115756.

22) Qi K, Lu N, Zhang S, Wang W, Wang Z, Guan J. 2021. Uptake of $\mathrm{Pb}(\mathrm{II})$ onto microplastic-associated biofilms in freshwater: Adsorption and combined toxicity in comparison to natural solid substrates. J Hazard Mater 411: 125115.

23) Kroenke $\mathrm{CH}$, Neugebauer R, Meyerhardt J, Prado CM, Weltzien E, Kwan ML, Xiao J, Caan BJ. 2016. Analysis of body mass index and mortality in patients with colorectal cancer using causal diagrams. JAMA Oncol 2: 11371145.

24) Valentin-Blasini L, Sadowski MA, Walden D, Caltabiano L, Needham LL, Barr DB. 2005. Urinary phytoestrogen concentrations in the U.S. population (1999-2000). J Expo Anal Environ Epidemiol 15: 509-523.

25) Perez-Cornago A, Appleby PN, Boeing H, Gil L, Kyro C, Ricceri F, Murphy N, Trichopoulou A, Tsilidis KK, Khaw KT, Luben RN, Gislefoss RE, Langseth H, Drake I, Sonestedt E, Wallstrom P, Stattin P, Johansson A, Landberg R, Nilsson LM, Ozasa K, Tamakoshi A, Mikami K, Kubo T, Sawada N, Tsugane S, Key TJ, Allen NE, Travis RC. 2018. Circulating isoflavone and lignan concentrations and prostate cancer risk: a meta-analysis of individual participant data from seven prospective studies including 2,828 cases and 5,593 controls. Int J Cancer 143: $2677-2686$.

26) Moreno MA. 2018. Vitamin D and your child. JAMA Pediatr 172: 708.

27) Elizondo-Montemayor L, Castillo EC, Rodriguez-Lopez C, Villarreal-Calderon JR, Gomez-Carmona M, TenorioMartinez S, Nieblas B, Garcia-Rivas G. 2017. Seasonal variation in vitamin $\mathrm{D}$ in association with age, inflammatory cytokines, anthropometric parameters, and lifestyle factors in older adults. Mediators Inflamm 2017: 5719461.

28) Libuda L, Timmesfeld N, Antel J, Hirtz R, Bauer J, Fuhrer D, Zwanziger D, Ozturk D, Langenbach G, Hahn D, Ring S, Peters T, Hinney A, Buhlmeier J, Hebebrand J, Grasemann C, Focker M. 2020. Effect of vitamin D deficiency on depressive symptoms in child and adolescent psychiatric patients: results of a randomized controlled trial. Eur J Nutr 59: 3415-3424.

29) Batai K, Murphy AB, Ruden M, Newsome J, Shah E, Dixon MA, Jacobs ET, Hollowell CM, Ahaghotu C, Kittles RA. 2017. Race and BMI modify associations of calcium and vitamin D intake with prostate cancer. $B M C$ Cancer 17: 64-77.

30) El Khoudary SR, Samargandy S, Zeb I, Foster T, de Boer IH, Li D, Budoff MJ. 2020. Serum 25-hydroxyvitamin-D and nonalcoholic fatty liver disease: Does race/ethnicity matter? Findings from the MESA cohort. Nutr Metab
Cardiovasc Dis 30: 114-122.

31) Kapoor S, Deppen SA, Paulson AB, Haddad D, Cook JP, Sandler KL. 2020. Education level predicts appropriate follow-up of incidental findings from lung cancer screening. J Am Coll Radiol 17: 613-619.

32) Moore CE, Radcliffe JD, Liu Y. 2014. Vitamin D intakes of adults differ by income, gender and race/ethnicity in the U.S.A., 2007 to 2010. Public Health Nutr 17: 756763.

33) Moore CE, Radcliffe JD, Liu Y. 2014. Vitamin D intakes of children differ by race/ethnicity, sex, age, and income in the United States, 2007 to 2010. Nutr Res 34: 499506.

34) Jiang W, Wu DB, Xiao GB, Ding B, Chen EQ. 2020. An epidemiology survey of vitamin D deficiency and its influencing factors. Med Clin (Barc) 154: 7-12.

35) Shim SY, Chae WJ, Kim HC, Park EC, Jang SI. 2018. Association between serum 25-hydroxyvitamin D levels and pulmonary function, among Korean adults, during 2010-2014, by sex, age, and body mass index. Respir Med 140: 32-38.

36) Cheema C, Grant BF, Marcus R. 1989. Effects of estrogen on circulating "free" and total 1,25-dihydroxyvitamin D and on the parathyroid-vitamin D axis in postmenopausal women. J Clin Invest 83: 537-542.

37) Packer E, Holloway L, Newhall K, Kanwar G, Butterfield G, Marcus R. 1990. Effects of estrogen on daylong circulating calcium, phosphorus, 1,25-dihydroxyvitamin $\mathrm{D}$, and parathyroid hormone in postmenopausal women. J Bone Miner Res 5: 877-884.

38) Chennaiah S, Vijayalakshmi V, Suresh C. 2010. Effect of the supplementation of dietary rich phytoestrogens in altering the vitamin D levels in diet induced osteoporotic rat model. J Steroid Biochem Mol Biol 121: 268-272.

39) Ruggiero B, Padwa BL, Christoph KM, Zhou S, Glowacki J. 2016. Vitamin D metabolism and regulation in pediatric MSCs. J Steroid Biochem Mol Biol 164: 287-291.

40) Duque G, El Abdaimi K, Macoritto M, Miller MM, Kremer R. 2002. Estrogens (E2) regulate expression and response of 1,25-dihydroxyvitamin D3 receptors in bone cells: changes with aging and hormone deprivation. Biochem Biophys Res Commun 299: 446-454.

41) Swami S, Krishnan AV, Peehl DM, Feldman D. 2005. Genistein potentiates the growth inhibitory effects of 1,25-dihydroxyvitamin D3 in DU145 human prostate cancer cells: role of the direct inhibition of CYP24 enzyme activity. Mol Cell Endocrinol 241: 49-61.

42) Lee SR, Park MY, Yang H, Lee GS, An BS, Park BK, Jeung EB, Hong EJ. 2018. 5alpha-dihydrotestosterone reduces renal Cyp24a1 expression via suppression of progesterone receptor. J Mol Endocrinol 60: 159-170.

43) Talaei M, Lee BL, Ong CN, van Dam RM, Yuan JM, Koh WP, Pan A. 2016. Urine phyto-oestrogen metabolites are not significantly associated with risk of type 2 diabetes: the Singapore Chinese health study. Br J Nutr 115: 1607-1615.

44) Cortes-Martin A, Selma MV, Tomas-Barberan FA, Gonzalez-Sarrias A, Espin JC. 2020. Where to look into the puzzle of polyphenols and health? The postbiotics and gut microbiota associated with human metabotypes. Mol Nutr Food Res 64: e1900952.

45) Halldin E, Eriksen AK, Brunius C, da Silva AB, Bronze M, Hanhineva K, Aura AM, Landberg R. 2019. Factors explaining interpersonal variation in plasma enterolactone concentrations in humans. Mol Nutr Food Res 63: 
e1801159.

46) Landete JM, Arqués J, Medina M, Gaya P, de Las Rivas, Muñoz R. 2016. Bioactivation of phytoestrogens: intestinal bacteria and health. Crit Rev Food Sci Nutr 56: 1826-1843.

47) Gilad LA, Tirosh O, Schwartz B. 2006. Phytoestrogens regulate transcription and translation of vitamin D receptor in colon cancer cells. J Endocrinol 191: $387-$ 398.

48) Chatterjee I, Lu R, Zhang Y, Zhang J, Dai Y, Xia Y, Sun J. 2020. Vitamin D receptor promotes healthy microbial metabolites and microbiome. Sci Rep 10: 7340.

49) Hobaus J, Tennakoon S, Heffeter P, Groeschel C, Aggarwal A, Hummel DM, Thiem U, Marculescu R, Berger W, Kallay E. 2016. Impact of CYP24A1 overexpression on growth of colorectal tumour xenografts in mice fed with vitamin D and soy. Int J Cancer 138: 440-450.

50) Yeung AWK, Tzvetkov NT, Balacheva AA, Georgieva MG, Gan RY, Jozwik A, Pyzel B, Horbanczuk JO, Novellino E, Durazzo A, Lucarini M, Camilli E, Souto EB, Atanasov AG, Santini A. 2020. Lignans: Quantitative analysis of the research literature. Front Pharmacol 11: 37.

51) Milder IEJ, Feskens EJM, Arts ICW, Bueno de Mesquita HB, Hollman PCH, Kromhout D. 2005. Intake of the plant lignans secoisolariciresinol, matairesinol, lariciresinol, and pinoresinol in Dutch men and women. J Nutr 5: 1202-1207.

52) Lampe JW. 2003. Isoflavonoid and lignan phytoestrogens as dietary biomarkers. Biomarkers of Nutritional Exposure and Nutritional Status 5: 956-964.

53) Kunisue T, Tanabe S, Isobe T, Aldous KM, Kannan K. 2010. Profiles of phytoestrogens in human urine from several Asian countries. J Agric Food Chem 58: 9838 9846.

54) Li H, Jia E, Jiao J. 2020. Phytoestrogens in NAFLD: Potential mechanisms of action. Horm Metab Res 52: 77-84.

55) Yang J, Wen L, Jiang Y, Yang B. 2019. Natural estrogen receptor modulators and their heterologous biosynthesis. Trends Endocrinol Metab 30: 66-76.

56) Barrea L, Muscogiuri G, Laudisio D, Pugliese G, de Alteriis G, Colao A, Savastano S. 2020. Influence of the Mediterranean diet on 25-hydroxyvitamin D levels in adults. Nutrients 12: 1439.

57) Sanghera DK, Sapkota BR, Aston CE, Blackett, PR. 2017. Vitamin D status, gender differences, and cardiometabolic health disparities. Ann Nutr Metab 70: 79-87. 